\title{
The Use of Bone Age in Clinical Practice - Part 1
}

\author{
David D. Martin ${ }^{a} \quad$ Jan M. Wit ${ }^{d} \quad$ Ze'ev Hochberg $^{f} \quad$ Lars Sävendahlg $^{g}$ \\ Rick R. van Rijn ${ }^{\mathrm{e}}$ Oliver Fricke ${ }^{\mathrm{b}}$ Noël Cameron ${ }^{\mathrm{i}} \quad$ Janina Caliebe $^{\mathrm{a}}$ \\ Thomas Hertel $^{j} \quad$ Daniela Kiepe ${ }^{c}$ Kerstin Albertsson-Wikland ${ }^{\text {h }}$ \\ Hans Henrik Thodberg ${ }^{k}$ Gerhard Binder ${ }^{a}$ Michael B. Ranke ${ }^{a}$ \\ a Pediatric Endocrinology and Diabetology, University Children's Hospital, Tübingen, b Children's Hospital, \\ University of Cologne, Cologne, and 'Division of Pediatric Nephrology, University Children's Hospital, Heidelberg,

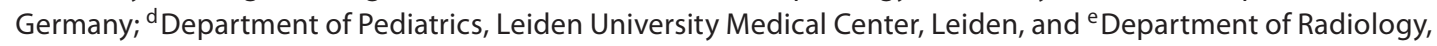 \\ Emma Children's Hospital/Academic Medical Center Amsterdam, Amsterdam, The Netherlands; \\ ${ }^{f}$ Meyer Children's Hospital, Rambam Medical Center, Haifa, Israel; 9 Pediatric Endocrinology Unit, Department of \\ Women's and Children's Health, Karolinska Institutet, Stockholm, and h GP-GRC, Department of Pediatrics, \\ Institute of Clinical Sciences, The Sahlgrenska Academy at University of Gothenburg, Gothenburg, Sweden; \\ 'Centre for Global Health and Human Development, Loughborough University, Loughborough, UK;

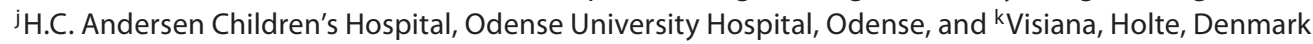

\section{Key Words}

Skeletal maturity $\cdot$ Bone age $\cdot$ Growth $\cdot$ Growth hormone deficiency $\cdot$ Familial short stature $\cdot$ Idiopathic short stature Small for gestational age $\cdot$ Turner syndrome

\footnotetext{
Abstract

This review examines the role of skeletal maturity ('bone age', BA) assessment in clinical practice. BA is mainly used in children with the following conditions: short stature (addressed in part 1 of this review), tall stature, early or late puberty, and congenital adrenal hyperplasia (all addressed in part 2). Various manual and automatic methods of BA assessment have been developed. Healthy tall children tend to have advanced BA and healthy short children tend to have delayed BA in comparison to chronological age. Growth hormone (GH) treatment of children with GH deficiency leads to a catch-up in BA that is usually appropriate for the height of the child. Response to $\mathrm{GH}$ is dependent on BA delay in young
}

children with idiopathic short stature, and GH dosage appears to affect BA acceleration. In chronic renal failure, BA is delayed until puberty but then increases due to increased sensitivity of the growth plate to sex steroids, thus further impairing adult height. The assessment of BA provides an important contribution to the diagnostic workup and management of children with short stature.

Copyright $\odot 2011$ S. Karger AG, Basel

\section{Introduction}

Skeletal maturity or bone age (BA) assessment is a routine procedure in all pediatric radiology departments. Pediatricians and endocrinologists recognize that the assessment of BA by means of a hand and wrist radiograph reflects the child's biological age. This is accomplished with a variety of methods, all of them comparing a given radiograph to various standards, averaging or summariz-

\section{KARGER}

Fax +4161306 1234

E-Mail karger@karger.ch

www.karger.com
(C) 2011 S. Karger AG, Basel

$1663-2818 / 11 / 0761-0001 \$ 38.00 / 0$

Accessible online at:

www.karger.com/hrp
Dr. David D. Martin

Pediatric Endocrinology and Diabetology, University Children's Hospital Hoppe-Seyler Strasse 1

DE-72076 Tübingen (Germany)

Tel.+49707 1298 3795, E-Mail david.martin@med.uni-tuebingen.de 
ing the maturity of several bones, followed by designation of a BA. In fact, a radiograph of the hand and wrist can at best reflect the maturity of the bones that are depicted on that film, and the recognition of the shapes and changes of configuration of bones provides only a limited insight into maturational processes [1]. Nevertheless, BA is considered an important indicator of maturity and is the only size-independent indicator of biological maturity routinely used from birth to adulthood. Many parameters correlate better with BA than with chronological age (CA) (e.g. height velocity, menarche, muscle mass and bone mineral mass [2]). BA is delayed in children with constitutional delay of growth, growth hormone $(\mathrm{GH})$ deficiency, hypothyroidism, malnutrition and chronic illness. It is advanced when a child has had prolonged elevation of sex steroid levels, as in precocious puberty or congenital adrenal hyperplasia. BA is often marginally advanced in children with tall stature, premature adrenarche or overweight. Genetic overgrowth syndromes, such as Sotos syndrome, Beckwith-Wiedemann syndrome and Marshall-Smith syndrome, are associated with significantly advanced BA.

\section{Technical and Methodological Considerations}

\section{Radiation Dose}

The effective radiation dose received by a child to obtain a radiograph for a BA assessment is less than 0.00012 $\mathrm{mSv}$ [3], equivalent to less than $20 \mathrm{~min}$ of natural background radiation or $2 \mathrm{~min}$ on a transatlantic flight [4]. The radiation is one part of the equation, the other is the susceptibility of tissue in the exposed area where some tissues are more susceptible than others (this is expressed in the tissue weighting factor, e.g. skin 0.02 , bone surface 0.05 , and bone marrow 0.5 ). The combination of dose and area (about $3 \%$ of body surface area) results in the effective dose of a hand-wrist radiograph. A conservative calculation resulted in a 40-year mortality risk of $5.1 \times$ $10^{-8}$ for a radiogram of the hand in a teenager based on a dose of $0.00015 \mathrm{mSv}$ [5]. Thus in either clinical or research settings, the risk of hand-wrist radiographs is minimal and should not prevent a well-designed research project from obtaining ethical approval.

\section{Methods of BA Rating}

Of the many methods published since the first study in 1898, two remain in frequent use: the Greulich and Pyle (GP) atlas and the Tanner-Whitehouse (TW) method [6]. The former compares radiographs of patients to reference images in the atlas each of which corresponds to a particular BA. Although the instructions for using this method suggest that each bone should be analyzed separately, most users inspect only some of these. The latter is based on applying scores to the maturity indicators observable on the individual bones of the hand and wrist after which a derived BA can be calculated from the sum of the scores. This technique is significantly more time-consuming compared to the way most clinicians and radiologists use the GP atlas. The radiographs are usually rated by radiologists or pediatricians. In most cases, the radiologists and pediatricians use the GP atlas, whereas some pediatric endocrinologists use the more finely scaled TW method [7]. Several studies have been published on the intraand interobserver variance of BA [8-11]. King et al. [8] provide an overview of many of these studies but it is difficult to draw any conclusions from their table because of conflicting results due to differing study designs, differing experience of the raters and differing measures of the interrater variability. A recent study found a standard error of 0.55 years among the readings of a group of 5 pediatric endocrinologists and a standard error of 0.61 years among 7 radiologists. (The paper only reports the intraclass correlation coefficient of 0.95 for each group; the data were kindly passed on to H.H.T. for calculation of the standard errors.) This is much better than the figure found by Bull et al. [12] (0.82 years), and slightly worse than that reported in a large dataset from Los Angeles (0.45 years) [13]. There are as yet no studies comparing the ratings of the staff and residents of different hospitals in different countries, which would permit an assessment of the actual routine, 'long-distance' interrater variation which is largely unknown today.

\section{The Possibilities and Limitations of Automated BA \\ Determination}

With the introduction of computers, the use of automated BA assessment became an attractive option. Early systems were relatively time-consuming and required a dedicated operator of the system. With the general progress in the field of medical imaging, more sophisticated software could be developed, such as BoneXpert (Visiana, Denmark), which is at present the only automated system cleared for clinical use in Europe. It assesses both GP and TW BA from a standard hand-wrist radiograph (fig. 1) [14]. The obvious advantage of the use of this fully automated software is the absence of variance between readings. This could mean a significant improvement of study quality in multicenter studies. Incorporating it into a picture archive and communication system - as en- 


\section{Color illustration online only!}

hanced structured reporting [15] - could spare radiologists and clinicians a relatively time-consuming activity.

Automated BA rating does not completely eliminate the radiologist evaluation, because there are other signs than BA that can be read from the image. To the trained pediatric radiologist, it can give a lead to possible underlying disorders (e.g. a relatively short fourth metacarpal in Turner's syndrome; see the section on Interpretation of Hand Radiographs). Thus, if the radiologist were to be left out of the diagnostic process altogether, this could (in rare cases) result in missed diagnoses. A second drawback in the case of BoneXpert is that the reported BA is a statistical mean of the BA of 13 individual bones (the same 13 bones as in the TW3 system). If the BA of a single bone as determined by BoneXpert deviates by more than 2.4 'years' from the mean, it is rejected. This could theoretically be a significant finding for the treating clinician (we were, however, unable to find a concrete example of such a case so it does not appear to be relevant). A third drawback is the restriction of the software to a BA range of 2.5-17 'years' for boys and 2.0-15.0 'years' for girls. However, this range suffices for most purposes. The fact that the software does not take into account the development of the carpals is a possible fourth drawback, although it is in line with Tanner and Whitehouse's recommendation to ignore the carpals in the primary measure of BA, the TW-RUS system. This change was published in the latest 2001 version of the TW method, where the TW 20-bone method was abandoned and the 13-bone TW-RUS method placed instead as the main BA measure [16]. While information on the development of the carpals does not play a role in adult height prediction, it has been suggested that it gives information about the maturation of the cuboid bones of the spine [1].

The relevant task for computers on pediatric hand radiographs is the quantitative evaluation of morphological changes distributed over many bones. The human eye is not optimal for grading such continuous changes; instead the strength of the eye is to detect qualitative deviations from normality. A pragmatic procedure for hand radiograph evaluation would thus be to distinguish between two different kinds of examinations: firstly, a straightforward assessment of skeletal maturity, in which case the radiograph could be handled automatically (this would, for example, be of value in follow-up and multicenter studies); secondly, a maturity assessment plus a general diagnostic evaluation of the hand-wrist radiograph, including potential diagnostic characteristics (e.g. lesions) on individual bones. The automated method rejects bone of poor radiographic quality, abnormal mor-

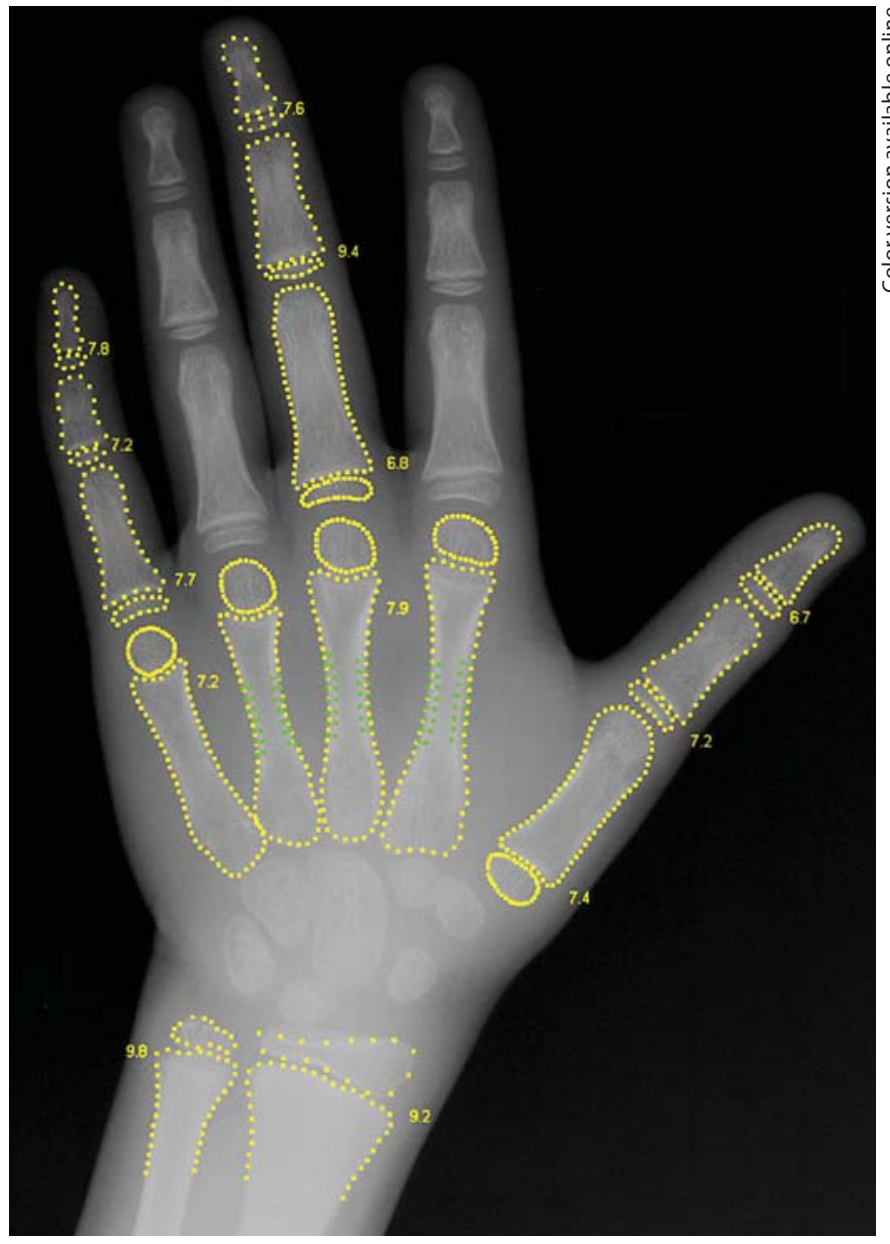

Fig. 1. Radiograph of the left hand showing the automatically detected contours of the distal radius and ulna and the metacarpals and phalanges by BoneXpert. Each of the 15 bones has a skeletal age assigned to it and the resulting mean skeletal age is reported.

phology or deviating BA. If fewer than 8 of the 13 bones survive this self-validation, the entire BA determination is rejected. Then a manual assessment is the only way to obtain a BA, and these cases are usually also associated with additional findings. In a validation of BoneXpert in children with short stature, BoneXpert rejected 14 of 1,097 radiographs due to abnormal morphology $(n=3)$, bad image quality $(n=3)$, BA being below the software's limit of $2 / 2.5$ years $(n=3)$, or inefficiency of the method due to poor contrast $(\mathrm{n}=1)$ or too small hands, which were analyzed correctly when magnified by $20 \%(n=3)$ [17]. In this study as well as in studies in children with precocious puberty [18] and in healthy Dutch children [14], the accuracy of BoneXpert, defined as the root mean square deviation from the manual rating, was between 
0.61 and 0.72 years. However, since there is no gold standard for BA, this is only an estimate. A more satisfactory definition of accuracy is obtained if one defines the average of a large number of manual ratings as the best approximation to a gold standard. Using this definition, BoneXpert's accuracy was found to be 0.52 years in healthy American children of Caucasian, African, Hispanic and Asian origin [13].

The precision of BoneXpert, defined as the standard deviation (SD) on a single reading, is 0 on the same X-ray and has been conservatively estimated at 0.17 and 0.18 years, respectively, for image series [19], and for assessing the difference between the left and right hand BA of a subject [20]. Comparable human rerating studies yielded a precision $S D$ in the range $0.25-0.82$ years $[12,16]$, depending on the experience of the rater. The impact of a poor precision can be illustrated by two examples: for a 13-year-old boy with a height of $160 \mathrm{~cm}$, BA values of 13 and 13.82 years yield a difference of $6.1 \mathrm{~cm}$ in adult height prediction, and for an 11-year-old girl with a height of 150 $\mathrm{cm}, \mathrm{BA}$ values of 11 and 11.82 years yield a difference of $4.0 \mathrm{~cm}$. In the search for an objective validation that goes beyond comparing the automated BA to that of trained manual raters, it was found that its correlation with growth potential, and therefore its ability to predict adult height, was at least as good as the GP rating and better than the TW rating of the raters of the First Zurich Longitudinal Study [21].

\section{Interpretation of Hand Radiographs: Going beyond the Overall $B A$}

The hand-wrist radiograph contains information that can guide the clinician to diagnose disorders/syndromes that may or may not be associated with abnormal BA [1, 22]. Examples include disorders affecting cartilage and/ or bone formation that often result in typical images such as broader and stunted bones (hypochondroplasia), irregular metaphysis and increased triangularization index (associated with the SHOX haploinsufficiency of the Turner syndrome and Léri-Weill syndrome) $[23,24]$, or shortness of the 4th and 5th metacarpals (pseudohypoparathyroidism). Many endocrine diseases are also associated with typical hand-wrist radiographic findings, for example rickets (abnormal growth plate mineralization), hypothyroidism (delayed carpal development), and hyperparathyroidism (cortical resorption). In addition, many chronic diseases have typical radiological findings that can be recognized on a hand-wrist radiograph, for example juvenile idiopathic arthritis (periarticular osteopenia and metaphyseal widening) and sarcoidosis (small lytic lesions). Also conditions of overgrowth have typical features such as Marfan syndrome (slender and gracile metacarpals/phalanges). Besides giving diagnostic clues, a hand-wrist radiograph may also give an estimate of bone mineral acquisition. For this, the automated BoneXpert method calculates a 'pediatric bone index' or 'bone health index' [25] by calculating the average length, width and cortical thickness of the 3 middle metacarpal bones [26].

When healthy children are split into groups of tall, average and short children, tall children have advanced skeletal maturity and tend to start puberty early and short children have delayed skeletal maturity and tend to enter puberty late $[27,28]$. When this is not the case, pathologies should be sought. However, short children tend to end up as short-normal adults and tall children end up as tall-normal adults $[28,29]$. This is especially the case in boys. Thus, when dividing the 120 boys of the First Zurich Longitudinal Study into tertiles of BA advancement at age 9 , the authors found that the BA-advanced boys became $6.4 \mathrm{~cm}$ taller as adults as compared to the BAdelayed boys ( $p<0.01$; unpublished); no such relationships were found for girls. The clinical significance of this is that short-statured boys with constitutional delay of growth and puberty will also be slightly short as adults, i.e. they cannot expect to fully catch up with their classmates. By the same token, children presenting in endocrine clinics and diagnosed with idiopathic short stature (ISS) $[30,31]$ or constitutional delay of growth [32] may end up slightly shorter than predicted according to the Bayley Pinneau method.

\section{The Use of BA in Clinical Presentations Involving Short Stature}

Having discussed the technical and methodological aspects of BA assessment, the rest of part 1 of this review addresses children who present with short stature. The participants of the 2009 International Workgroup on Skeletal Maturity agreed that the assessment of skeletal maturity is always recommendable as part of the routine workup for both diagnostic and prognostic purposes at first presentation of a child with short stature. Further, regular assessment of BA is recommendable during treatments that affect the GH or sex steroid pathways because these treatments affect skeletal maturation and adult height prediction. Therefore, most medical trials involving these pathways will include BA assessments. 


\section{Constitutional Delay of Growth and Puberty}

Constitutional delay of growth and puberty is a diagnosis that can only be definitely made retrospectively: the children enter puberty later than the norm but usually attain a normal adult height. In various reports [33-35], this clinical condition is considered as one of the subgroups of ISS, i.e. nonfamilial short stature with delayed onset of puberty. A positive family history for constitutional delay of growth and puberty may be found. BA is normally assessed in the diagnostic workup of these children and a lack of delay in skeletal maturity should prompt the search for another diagnosis. Since all healthy normal short children are expected to have a delayed skeletal maturity, the question arises as to how constitutional delay of growth and puberty should be defined. A BA delay of more than 2 'years' has arbitrarily been used as an inclusion criterion for constitutional delay of growth and puberty $[36,37]$. Studies of children and youth with constitutional delay of growth and puberty tend to report a BA that is not quite as delayed as the 'height age' (i.e. the mean age corresponding to the child's height). In many of these children, adult height may be low due to a combination of delayed puberty and relatively short parents $[36,37]$.

Hero et al. [38] reported on the near-adult height of boys who had taken part in a trial involving low-dose testosterone ( $1 \mathrm{mg} / \mathrm{kg}$ i.m. every 4 weeks for 6 months) plus either placebo $(n=8)$ or the aromatase inhibitor letrozole $(2.5 \mathrm{mg}$ /day p.o.; $\mathrm{n}=9)$ for 12 months. Letrozole appeared to have conveyed a net advantage over placebo with regard to near-adult height although the data are difficult to interpret due to the taller mid-parental height of the letrozole-treated group. This study also showed that the predicted adult height at 18 months after start of treatment overestimated near-adult height by about $5 \mathrm{~cm}$. Hence studies of the use of low-dose testosterone [39, 40] or oxandrolone [41] need to be interpreted with caution if they report only the effect on BA-dependent predicted adult height and have not followed the children until (near-)adult height.

\section{Idiopathic Short Stature}

$\mathrm{BA}$ is not part of the diagnostic criteria in the currently used definition of ISS: height $<-2$ SDS for appropriate age references without discernible cause $[34,42]$. BA is usually retarded in ISS, with a mean delay of approximately 1.5-2 'years' (range 0-4 'years') at 8-11 years of age $[43,44]$. An absence of BA delay is a strong argument against any secondary growth disorder such as GH deficiency or hypothyroidism. A substantial delay in BA can be a sign of 'constitutional delay of growth and puberty' or GH deficiency, although the delay in BA does not always imply that puberty will also be delayed. The handwrist radiograph may also give information on syndromes and conditions that exclude ISS (see the section on Interpretation of Hand Radiographs).

As long as there are still no adult height prediction models specifically developed for children with short stature, one should be cautious about predicting adult stature: a BA delay of 4 'years' is associated with an $8-\mathrm{cm}$ overprediction (calculated as predicted by the BayleyPinneau tables minus achieved height), while in ISS children with no BA delay adult height is underestimated by the Bayley-Pinneau tables [31, 43]. In girls, the prediction is generally more accurate than in boys [31].

If children with ISS are treated with GH, BA should be carefully monitored, preferably by the same rater or by an automated system [17]. In a Dutch study using a high dosage of $71 \mu \mathrm{g} / \mathrm{kg} / \mathrm{day}$, BA advanced as fast as growth in terms of SDS scores, so that adult height prediction at the onset of puberty, as well as attained adult height, were no different from untreated controls [45]. In contrast, there was a positive net effect of GH using dosages of 30-67 $\mu \mathrm{g} /$ $\mathrm{kg} /$ day $[44,46]$ and in a study using an IGF-I titration dosing scheme [47]. The interpretation of the effect of BA on the long-term outcome of GH treatment in ISS is dependent on the initial BA delay: the average effect, compared to untreated controls, of an appropriately dosed GH treatment of $45 \mu \mathrm{g} / \mathrm{kg} /$ day was $7 \mathrm{~cm}$, but it was only $2 \mathrm{~cm}$ when there was no BA delay, and $10 \mathrm{~cm}$ in children with a BA delay of 4 'years' $[43,44]$. Thus the children with familial short stature and no BA delay show the poorest growth response to GH treatment [45].

\section{Short Children Born Small for Gestational Age}

A child is given the diagnosis small for gestational age (SGA) if its birth weight and/or birth length for gestational age are $<-2$ SDS according to their regional ethnic reference. About $3 \%$ of all newborns will be classified SGA and about $10 \%$ of these children fail to grow into the normal range within the first 3 years of life. These children born SGA without catch-up growth, usually defined as having a childhood height $<-2$ SDS at $>3$ years of age, run a high risk of remaining short.

In children born SGA, BA is often relatively delayed until 8 years of age [48]. In untreated children, the BA delay seems to vary between $1[48]$ and $2[49,50]$ 'years' and is slightly less delayed than one would expect for their height. Prior to the onset of puberty, possibly during the time of the adrenarche, there is a rapid acceleration of BA 
in many children born SGA. The pubertal growth spurt often occurs early and reduced in magnitude and the former BA delay can be suddenly lost without the 'extra growing time' one might have expected from their initial BA delay. An adult height prediction model for children born SGA has yet to be developed and tested. This will be difficult since the diagnosis 'SGA' comprises a heterogeneous group of known and unknown conditions.

The spontaneous catch-up of BA in relation to CA over a 3-year prepubertal observation phase has been described as being $<1$ 'year' [49] or 1 'year' [48], with large interindividual variability. Under $\mathrm{GH}$ treatment, it was between 1.0 [49] and 1.5 'years' [48, 50, 51]. The larger the BA delay at the start of $\mathrm{GH}$ treatment, the higher its acceleration in the 1st year of GH treatment [49]. GH dose dependency has been controversially described: one study showed no GH dosage dependency [49], while a meta-analysis described faster bone maturation with higher GH dosage [52].

It has not yet been established whether SGA children with a lack of corresponding BA delay have a poorer response to $\mathrm{GH}$. Bone maturation during $\mathrm{GH}$ treatment is proportional to height gain: The $\Delta \mathrm{BA} / \Delta \mathrm{CA}$ ratio seems to be a good predictor for 3-year height gain [48]. Dose reduction should be considered if BA advances by more than 2 'years' in 1 year.

\section{GH Deficiency}

BA is delayed in prepubertal children with GH deficiency with a mean of $2 \pm 1$ 'years' at age 6-10 years. In prepubertal children, a BA that is equal to or advanced in relation to $\mathrm{CA}$ makes $\mathrm{GH}$ deficiency very unlikely (unless the onset of the deficiency was very recent, or unless GH deficiency is accompanied by increased secretion of sex steroids).

$\mathrm{BA}$ is expected to accelerate under $\mathrm{GH}$ treatment of prepubertal children with GH deficiency, and more so during puberty. Despite this advancement, BA still remains delayed in most children during treatment. In a Swedish study of 283 prepubertal GH deficiency children, the BA delay decreased from $-2.0 \pm 1.0$ 'years' at GH start to $-1.8,-1.5$, and -1.2 after 1,2 and 3 years, respectively. It is common practice for BA to be monitored during GH treatment. In particular, BA should be monitored at least after 1 and 2 years of GH treatment in all children receiving $\mathrm{GH}$ irrespective of their diagnosis.

\section{Turner Syndrome}

The missing short arm of the X chromosome in Turner syndrome leads to SHOX haploinsufficiency associat- ed with a variable degree of short stature, skeletal disproportion, Madelung deformity, epiphyseal abnormalities, discordant growth and maturation and slight defects of matrix and mineralization [53]. However, none of these are so severe as to hinder assessment of skeletal maturity. Already in 1938, Henry Turner [54] noted a delayed maturity in the patients he first described. A slight delay in BA has since been found in all subsequent studies, using various methods of assessment [53, 55-60]. More precisely, if no hormonal treatment is initiated, BA appears to be delayed in the first assessments after birth and then more or less maintains this slight delay until the age of about 10 years, after which the delay drastically increases in accordance with the estrogen deficiency of these girls.

Prepubertal girls with Turner syndrome who present for GH treatment usually have a BA below CA before treatment. BA increases slightly during the first years of treatment and then remains age-appropriate until the age of about 10 years when BA decreases profoundly in most girls until estrogen replacement (if needed) is started. Estrogen replacement leads to an advancement of BA at the cost of adult height and should therefore not be started too early [61]. Today, estrogen can be initiated with very low doses of $17 \beta$ estrogen patches [62] but the effect of such a treatment on BA and adult height has yet to be evaluated [63].

\section{Chronic Renal Failure}

A reduction in the glomerular filtration rate to less than $60 \mathrm{ml} / \mathrm{min} / 1.73 \mathrm{~m}^{2}$ is frequently associated with growth disturbances [64]. The degree of growth failure is influenced by the primary kidney disease such as hypo-/ dysplastic nephropathies, glomerulopathies, tubular or interstitial nephropathies [64]. Contributing mechanisms to growth disturbances are malnutrition, metabolic acidosis, electrolyte disturbances, renal anemia, and hormonal disturbances including the somatotropic hormone axis, the gonadotropic hormone axis, $\mathrm{PTH}$, and vitamin D metabolism (renal osteodystrophy) [64]. The resorption front in the growth plate appears as a pseudogrowth plate in both the radius and ulna, suggesting a dissociation across the interface where osteogenesis takes place [1]. The increase in growth plate cartilage and hypertrophic zone heights (which are positively correlated with serum urea nitrogen in uremic rats [65]) compromise the assessment of $\mathrm{BA}$. In chronic renal failure, $\mathrm{BA}$ is delayed, the pubertal growth spurt starts with a delay of 2.5 'years' and the pubertal growth period is subnormal (1 year in boys; 1.5 years girls) [66]. Height SDS is gradually lost during the pubertal growth spurt, resulting in an 
average relative height deficit of -2.9 SDS in boys and -2.3 SDS in girls [66]. BA is retarded before puberty and accelerates dramatically at the start of puberty due to increased sensitivity of the uremic growth plate to sex steroids [67]. As growth (proliferation) cannot keep pace with differentiation (bone maturation), growth potential may be irreversibly lost during puberty in chronic renal failure, leading to a 3 - to $10-\mathrm{cm}$ overprediction of adult height [68].

\section{Conclusion}

In part 1 of this review on the use of BA in clinical practice, we have addressed technical issues around BA assessment and examined its role in modern pediatric management of children with short stature. BA is an integral part of the workup in these patients and close collaboration with pediatric radiologists is essential to exclude underlying disorders, such as skeletal dysplasias. The advent of automated techniques could facilitate standardization and international studies although research in this field is still mandatory.

\section{Acknowledgements}

This study is partly indebted to the participants of the International Workgroup on Skeletal Maturity: Kerstin AlbertssonWikland (Sweden), Gary Butler (UK), Janina Caliebe (Germany), Noël Cameron (UK), Oliver Fricke, (Germany), Thomas Hertel (Denmark), Ze'ev Hochberg (Israel), Daniela Kiepe, (Germany), David D. Martin (Germany), John Pettifor, (South Africa), Moshe Phillip (Israel), Michael B. Ranke (Germany), Rick R. van Rijn (The Netherlands), Lars Sävendahl (Sweden), Hans Henrik Thodberg (Denmark), George Werther (Australia), Jan M. Wit (The Netherlands) and Angelika Zierl (Germany). The 2009 Meeting of the Workgroup in Tübingen was partly supported by Novo Nordisk.

\section{Disclosure Statement}

Hans Henrik Thodberg is the owner of Visiana, which holds and markets the BoneXpert medical device for automated determination of bone age. The other authors have no conflict of interest.

\section{References}

1 Hochberg Z: Endocrine Control of Skeletal Maturation. Basel, Karger, 2002.

$\checkmark 2$ Bass S, Pearce G, Bradney M, Hendrich E, Delmas PD, Harding A, Seeman E: Exercise before puberty may confer residual benefits in bone density in adulthood: studies in active prepubertal and retired female gymnasts. J Bone Miner Res 1998;13:500-507.

$\checkmark 3$ Huda W, Gkanatsios NA: Radiation dosimetry for extremity radiographs. Health Phys 1998;75:492-499.

4 Thorne MC: Background radiation: natural and man-made. J Radiol Prot 2003;23:29-42.

$\checkmark 5$ Jung $\mathrm{H}$ : The radiation risks from X-ray studies for age assessment in criminal proceedings. Rofo 2000;172:553.

6 Greulich W, Pyle S: Radiographic Atlas of the Skeletal Development of the Hand and Wrist, ed 2. Stanford, Stanford University Press, 1959.

7 Buckler JM: How to make the most of bone ages. Arch Dis Child 1983;58:761-763.

$>8$ King D, Steventon D, O’Sullivan M, Cook A Hornsby V, Jefferson I, King P: Reproducibility of bone ages when performed by radiology registrars: an audit of Tanner and Whitehouse II versus Greulich and Pyle methods. Br J Radiol 1994;67:848-851.
-9 van Rijn RR, Lequin MH, Robben SGF, Hop WCJ, van Kuijk C: Is the Greulich and Pyle atlas still valid for Dutch Caucasian children today? Pediatr Radiol 2001;31:748-752.

10 Lynnerup N, Belard E, Buch-Olsen K, Sejrsen B, Damgaard-Pedersen K: Intra- and interobserver error of the Greulich-Pyle method as used on a Danish forensic sample. Forensic Sci Int 2008;179:1-6

11 Johnson GF, Dorst JP, Kuhn JP, Roche AF, Davila GH: Reliability of skeletal age assessments. Am J Roentgenol Radium Ther Nucl Med 1973;118:320-327.

12 Bull R, Edwards P, Kemp P, Fry S, Hughes I: Bone age assessment: a large scale comparison of the Greulich and Pyle, and Tanner and Whitehouse (TW2) methods. Arch Dis Child 1999;31:172-173.

13 Thodberg HH, Sävendahl L: Validation and reference values of automated bone age determination for four ethnicities. Acad Radiol 2010;17:1425-1432.

14 Thodberg HH, Kreiborg S, Juul A, Pedersen KD: The BoneXpert method for automated determination of skeletal maturity. IEEE Trans Med Imaging 2009;28:52-66.

15 Hussein R, Engelmann U, Schroeter A, Meinzer HP: DICOM structured reporting. Part 2. Radiographics 2004;24:897-909.
16 Tanner JM, Healy M, Goldstein H, Cameron $\mathrm{N}$ : Assessment of Skeletal Maturity and Prediction of Adult Height (TW3 Method), ed 3. London, WB Saunders, 2001.

17 Martin DD, Deusch D, Schweizer R, Binder G, Thodberg HH, Ranke MB: Clinical application of automated Greulich-Pyle bone age determination in children with short stature. Pediatr Radiol 2009;39:598-607.

18 Martin DD, Stahl K, Schweizer R, Thodberg $\mathrm{HH}$, Ranke MB: Validation of BoneXpert in children with precocious puberty. Horm Res 2008;70(suppl 1):73.

19 Martin DD, Sato K, Sato M, Thodberg HH, Tanaka T: Validation of the BoneXpert method for automated determination of bone age on Japanese children. Horm Res Paediatr 2010;73:398-404.

20 Martin DD, Neuhof J, Jenni OG, Ranke MB, Thodberg HH: Automatic determination of left and right hand bone age in the First $\mathrm{Zu}$ rich Longitudinal Study. Horm Res Paediatr 2010;74:50-55.

21 Thodberg HH, Jenni OG, Ranke MB, Martin DD: Validation of bone age methods through prediction of final adult height. Horm Res Paediatr 2010;73:398-404. 
22 Scanderbeg AC, Dallapiccola B: Congenital defects, malformation syndromes and skeletal dysplasias; in Guglielmi G, van Kuijk C, Genant HK (eds): Fundamentals of Hand and Wrist Imaging. Berlin, Springer, 2001.

23 Even L, Bronstein V, Hochberg Z: Bone maturation in girls with Turner's syndrome. Eur J Endocrinol 1998; 138:59.

24 Binder G, Ranke MB, Martin DD: Auxology is a valuable instrument for the clinical diagnosis of SHOX haploinsufficiency in schoolage children with unexplained short stature. J Clin Endocrinol Metab 2003;88:48914896.

-25 Thodberg HH, van Rijn RR, Tanaka T, Martin DD, Kreiborg S: A pediatric bone index derived by automated radiogrammetry. Osteoporos Int 2010;21:1391-1400.

-26 Martin DD, Heckmann C, Jenni OG, Ranke MB, Binder G, Thodberg HH: Metacarpal thickness, width, length and medullary diameter in children - reference curves from the First Zuerich Longitudinal Study. Osteoporosis International 2011;22:1525-1536.

$\checkmark 27$ Sproul A, Peritz E: Assessment of skeletal age in short and tall children. Am J Phys Anthropol 1971;35:433-439.

28 Prader A, Largo RH, Molinari L, Issler C: Physical growth of Swiss children from birth to 20 years of age. First Zurich longitudinal study of growth and development. Helv Paediatr Acta Suppl 1989;52:1-125.

-29 Thodberg HH, Jenni OG, Caflisch J, Ranke MB, Martin DD: Prediction of adult height based on automated determination of bone Age. J Clin Endocrinol Metab 2009;94:48684874.

30 Ranke MB, Grauer ML, Kistner K, Blum WF, Wollmann HA: Spontaneous adult height in idiopathic short stature. Horm Res 1995;44: 152-157.

- 31 Wit JM, Kamp GA, Rikken B: Spontaneous growth and response to growth hormone treatment in children with growth hormone deficiency and idiopathic short stature. Pediatr Res 1996;39:295-302.

- 32 LaFranchi S, Hanna CE, Mandel SH: Constitutional delay of growth: expected versus final adult height. Pediatrics 1991;87:82-87.

33 Rekers-Mombarg LT, Wit JM, Massa GG, Ranke MB, Buckler JM, Butenandt O, Chaussain JL, Frisch H, Leiberman E: Spontaneous growth in idiopathic short stature. European Study Group. Arch Dis Child 1996;75:175180.

- 34 Cohen P, Rogol AD, Deal CL, Saenger P, Reiter EO, Ross JL, Chernausek SD, Savage MO, Wit JM: Consensus statement on the diagnosis and treatment of children with idiopathic short stature: a summary of the Growth Hormone Research Society, the Lawson Wilkins Pediatric Endocrine Society, and the European Society for Paediatric Endocrinology Workshop. J Clin Endocrinol Metab 2008;93:4210.
5 Deodati A, Cianfarani S: Impact of growth hormone therapy on adult height of children with idiopathic short stature: systematic review. BMJ 2011;342:c7157.

-36 Crowne EC, Shalet SM, Wallace WH, Eminson DM, Price DA: Final height in boys with untreated constitutional delay in growth and puberty. Arch Dis Child 1990;65:1109-1112.

37 Albanese A, Stanhope R: Predictive factors in the determination of final height in boys with constitutional delay of growth and puberty. J Pediatr 1995; 126:545-550.

38 Hero M, Wickman S, Dunkel L: Treatment with the aromatase inhibitor letrozole during adolescence increases near final height in boys with constitutional delay of puberty. Clin Endocrinol 2006;64:510-513.

- 39 Butler GE, Sellar RE, Walker RF, Hendry $\mathrm{M}$, Kelnar CJ, Wu FC: Oral testosterone undecanoate in the management of delayed puberty in boys: pharmacokinetics and effects on sexual maturation and growth. J Clin Endocrinol Metab 1992;75:37-44.

-40 Richman RA, Kirsch LR: Testosterone treatment in adolescent boys with constitutional delay in growth and development. N Engl J Med 1988;319:1563-1567.

41 Wilson DM, McCauley E, Brown DR, Dudley R: Oxandrolone therapy in constitutionally delayed growth and puberty. Pediatrics 1995;96:1095.

42 Ranke MB: Towards a consensus on the definition of idiopathic short stature. Horm Res 1996;45:64-66.

43 Wit JM, Rekers-Mombarg LTM: Final height gain by GH therapy in children with idiopathic short stature is dose dependent. J Clin Endocrinol Metab 2002;87:604.

44 Albertsson-Wikland K, Aronson AS, Gustafsson J, Hagenas L, Ivarsson SA, Jonsson B, Kristrom B, Marcus C, Nilsson KO, Ritzen EM, Tuvemo T, Westphal O, Aman J: Dosedependent effect of growth hormone on final height in children with short stature without growth hormone deficiency. J Clin Endocrinol Metab 2008;93:4342-4350.

45 Kamp GA, Waelkens JJJ, Muinck KeizerSchrama S, Delemarre-Van de Waal H, Verhoeven-Wind L, Zwinderman AH, Wit JM: High dose growth hormone treatment induces acceleration of skeletal maturation and an earlier onset of puberty in children with idiopathic short stature. Arch Dis Child 2002;87:215-220.

46 Wit JM, Rekers-Mombarg LTM, Cutler GB, Crowe B, Beck TJ, Roberts K, Gill A, Chaussain JL, Frisch H, Yturriaga R: Growth hormone $(\mathrm{GH})$ treatment to final height in children with idiopathic short stature: evidence for a dose effect. J Pediatr 2005;146:45-53.

47 Cohen P, Rogol AD, Howard CP, Bright GM, Kappelgaard AM, Rosenfeld RG, on behalf of the American Norditropin Study Group: Insulin growth factor-based dosing of growth hormone therapy in children: a randomized, controlled study. J Clin Endocrinol Metab 2007;92:2480-2486.
48 Arends NJT, Boonstra VH, Mulder PGH, Odink RJH, Stokvis-Brantsma WH, RongenWesterlaken C, Mulder JC, Delemarre-Van de Waal H, Reeser HM, Jansen M, Waelkens JJJ, Hokken-Koelega ACS: GH treatment and its effect on bone mineral density, bone maturation and growth in short children born small for gestational age: 3 -year results of a randomized, controlled GH trial. Clin Endocrinol 2003;59:779-787.

49 Darendeliler F, Ranke MB, Bakker B, Lindberg A, Cowell CT, Albertsson-Wikland K, Reiter EO, David A: Bone age progression during the first year of growth hormone therapy in pre-pubertal children with idiopathic growth hormone deficiency, Turner syndrome or idiopathic short stature, and in short children born small for gestational age. Horm Res 2005;63:40-47.

50 Jung H, Land C, Nicolay C, De Schepper J, Blum WF, Schoenau E: Growth response to an individualized versus fixed dose $\mathrm{GH}$ treatment in short children born small for gestational age: the OPTIMA study. Eur J Endocrinol 2009;160:149.

51 Martin DD, Deusch D, Schweizer R, Binder G, Ranke MB: Knochenalter und Knochendichte vor und während Wachstumshormonbehandlung bei kleinwüchsigen SGA Kindern. Ergebnisse der BoneXpert Methode. 6. Intersiziplinärer SGA-Workshop der IPEP, Kloster Schöntal, 2008.

52 de Zegher F, Butenandt O, Chatelain P, Albertsson-Wikland K, Jonsson B: Growth hormone treatment of short children born small for gestational age: reappraisal of the rate of bone maturation over 2 years and metanalysis of height gain over 4 years. Acta Paediatr Suppl 1997;423:207.

53 Park E, Bailey JD, Cowell CA: Growth and maturation of patients with Turner's syndrome. Pediatr Res 1983;17:1.

54 Turner HH: A syndrome of infantilism, congenital webbed neck, and cubitus valgus. Endocrinology 1938;23:566-574.

55 Acheson RM, Zampa GA: Skeletal maturation in ovarian dysgenesis and Turner's syndrome. Obstetr Gynecol Surv 1961;16:683.

56 Weill J, Bernfeld J: Le trouble de la croissance dans le syndrome de Turner. Rev Fr Endocrinol Clin 1971;12:483-502.

57 Brook CG, Murset G, Zachmann M, Prader A: Growth in children with 45, XO Turner's syndrome. Br Med J 1974;49:789-795.

58 Webber M, Puck MH, Maresh MM, Goad WB, Robinson A: Skeletal maturation of children with sex chromosome abnormalities. Pediatr Res 1982;16:343.

59 Ranke MB, Pflüger H, Rosendahl W, Stubbe P, Enders H, Bierich JR, Majewski F: Turner syndrome: spontaneous growth in 150 cases and review of the literature. Eur J Pediatr 1983;141:81-88. 
60 Schwarze CP, Arens D, Haber HP, Wollmann HA, Binder G, Mayer EIE, Ranke MB: Bone age in 116 untreated patients with Turner's syndrome rated by a computer-assisted method (CASAS). Acta Paediatr 1998;87: 1146-1150.

61 Chernausek SD, Attie KM, Cara JF, Rosenfeld RG, Frane J: Growth hormone therapy of Turner syndrome: the impact of age of estrogen replacement on final height. Genentech, Inc, Collaborative Study Group. J Clin Endocrinol Metab 2000;85:2439-2445.

-62 Ankarberg-Lindgren C, Elfving M, Wikland KA, Norjavaara E: Nocturnal application of transdermal estradiol patches produces levels of estradiol that mimic those seen at the onset of spontaneous puberty in girls. J Clin Endocrinol Metab 2001;86:3039.
63 Nabhan ZM, DiMeglio LA, Qi R, Perkins SM, Eugster EA: Conjugated oral versus transdermal estrogen replacement in girls with Turner syndrome: a pilot comparative study. J Clin Endocrinol Metab 2009;94: 2009-2014.

64 Haffner D, Nissel R: Comprehensive Pediatric Nephrology. Philadelphia, Mosby/Elsevier, 2008.

65 Fernandez-Fuente M, Santos F, Carbajo-Perez E, Rodriguez J, Weruaga A, Amil B, Molinos I, Garcia E: Growth plate height of uremic rats is influenced by severity and duration of renal failure. Pediatr Nephrol 2004; 19:187-192.
66 Schaefer F, Seidel C, Binding A, Gasser T, Largo RH, Prader A, Scharer K: Pubertal growth in chronic renal failure. Pediatr Res 1990;28:5.

67 Van Steenbergen MW, Wit JM, Donckerwolcke R: Testosterone esters advance skeletal maturation more than growth in short boys with chronic renal failure and delayed puberty. Eur J Pediatr 1991;150: 676-680.

68 Nissel R, Brazda I, Feneberg R, Wigger M, Greiner C, Querfeld U, Haffner D: Effect of renal transplantation in childhood on longitudinal growth and adult height. Kidney Int 2004;66:792-800 